\title{
Oxygen affinity of hemoglobin and peripheral nerve degeneration in experimental diabetes
}

\author{
Shereen D. Farber ${ }^{1}$, Mark O. Farber ${ }^{2}$, George Brewer ${ }^{3}$, Carolyn J. Magnes ${ }^{2}$ and \\ Richard G. Peterson ${ }^{1}$ \\ ${ }^{1}$ Indiana University School of Medicine, and ${ }^{2}$ Roudebush VA Medical Center. Indianapolis, IN 46202 (U.S.A.), and ${ }^{3}$ Department of Human Genetics, \\ University of Michigan Ann Arbor, MI 48109 (U.S.A.)
}

(Received 6 August, 1990)

(Revised, received 19 October, 1990)

(Accepted 23 October, 1990)

Key words: Affinity hypoxia; ATP; Red blood cell; 2,3-Diphosphoglycerate; $\mathbf{P}_{50}$; Peripheral neuropathy; Hypoglycemia; Experimental diabetes mellitus

\section{Summary}

Peripheral neuropathy remains a major complication of diabetes. Numerous etiological theories of metabolic and/or vascular disturbances have been suggested including decreased endoneurial oxygen tension with presumed tissue hypoxia. Increases in the affinity of hemoglobin for oxygen ( $\mathrm{Hb}-\mathrm{O}_{2}$ affinity) may also produce tissue hypoxia and such $\mathrm{Hb}-\mathrm{O}_{2}$ affinity changes have been implicated in the pathogenesis of diabetic microangiopathy. In order to test whether affinity hypoxia might contribute to the development of diabetic peripheral neuropathy, we have utilized a rat model of high and normal $\mathrm{Hb}-\mathrm{O}_{2}$ affinity produced by backcrossing animals with increased and decreased levels of 2,3-diphosphoglycerate (DPG). Diabetes was induced in ten high and ten low DPG animals with a tail vein injection of $55 \mathrm{mg} / \mathrm{kg}$ streptozotocin (STZ). Five animals in each group were treated with $2.4 \mathrm{U}$ protamine zinc insulin (PZI)/day while the remaining animals were untreated. All rats were killed after 30 days, sections of tibial and sural nerve were rapidly removed and processed for teased fiber analysis. A minimum of 125 axons were assessed per nerve for E degeneration (myelin ovoids) using the classification developed by Dyck et al. Untreated animals, regardless of DPG levels, demonstrated $0 \%$ neuropathy. In contrast, all insulin-treated animals showed degeneration $(0.4-17 \%)$ that inversely correlated with the DPG level $(r=-0.59, P<0.04)$. The results of this study suggest that the level of RBC DPG (and presumably the $\mathrm{Hb}-\mathrm{O}_{2}$ affinity) with its attendant effect on tissue oxygen release may play a role in the development of peripheral neuropathy in STZ-induced diabetic rats treated with insulin.

\section{Introduction}

Peripheral nerve degeneration is a major source of morbidity in diabetes mellitus. At least 2.5 million patients in the United States alone have been diagnosed as having diabetic neuropathy (Thomas et al. 1984). The etiology and/or pathogenesis of this diabetic sequel remains elusive although many theories seeking to explicate it are extant. These theories generally fall into two categories, vascular and metabolic, and have been reviewed extensively (Dyck 1989; Dyck et al. 1985; Greene et al. 1988; Low 1987; Windebank 1983). The majority of these theories have focused on the diabetic state per se with little emphasis on

Correspondence to: Mark O. Farber, M.D. (111P), Roudebush VA Medical Center, 1481 W. 10th Street, Indianapolis, IN 46202, U.S.A. Tel.: (317)635-7401. the treatment methods and their potential contributory role in exacerbating neuropathy symptoms.

Ditzel (1980) has hypothesized that increases in the oxygen affinity of hemoglobin producing tissue hypoxia (affinity hypoxia) associated with insulin treatment may be responsible for many of the pathologic changes seen in the microcirculation of diabetes with microangiopathy. He was able to demonstrate that in diabetes, alterations in hemoglobin-oxygen $\left(\mathrm{Hb}-\mathrm{O}_{2}\right)$ affinity were correlated inversely with levels of red blood cell (RBC) 2,3-diphosphoglycerate (DPG; Ditzel 1980; Ditzel et al. 1975, 1977; Standl et al. 1976). We postulated that neuropathic changes observed in the peripheral nerves of insulin-treated experimental diabetic rats might also be related to affinity hypoxia and DPG levels via microvascular changes in the vasa nervosum. Therefore, we predicted that animals with high RBC levels of DPG would exhibit less peripheral nerve degeneration than animals with normal levels of RBC DPG 
when both were rendered diabetic and treated with insulin. The availability of an animal model with high and normal DPG strains enabled us to test our hypothesis. The model was developed by one of the authors by backcrossing high DPG heterozygous Long Evans Hooded rats to homozygous normal DPG Lou rats (Brewer et al. 1979).

\section{Materials and methods}

Fifteenth generation 8-week-old male rats as described were utilized. Ten normal DPG and 10 high DPG rats were all rendered diabetic by tail vein injection of streptozotocin $(55 \mathrm{mg} / \mathrm{kg})$. Five animals in each group were randomly selected for daily treatment with protamine zinc insulin (PZI: 2.4 units/day) while 5 in each group were untreated. Baseline measures included weight, hematocrit, plasma glucose (Beckman Glucose Analyzer, Beckman Instruments, Fullerton, CA), RBC DPG and ATP (Sigma kits, Sigma Technical Bulletins 366 and 35-UV). DPG and ATP were measured individually by separate methods. The DPG values and the ATP values were then added together since their effect on $\mathrm{O}_{2}$ affinity is equal. Measures were repeated at intervals for the duration of the study. After 4 wceks of treatment, plasma insulin levels were assayed from serum obtained at death by single antibody equilibrium method using Wright guinea pig serum antiporcine insulin modification of Heding's method (Heding 1972). Glucagon values were also obtained at death from serum using Eisentraut's modification of Unger's method (Unger et al. 1962). At baseline and during the study, blood was obtained via tail vein cannulation while blood at death was from heart puncture. Prior to sacrifice, animals were anesthetized with Nembutol. The sural and tibial nerves were fixed in $1.5^{\circ}$ o glutaraldehyde, $0.05^{\circ} \%$ paraformaldehyde in $0.08 \mathrm{M}$ Sørensen's phosphate buffer for $3 \mathrm{~h}$ at room temperature and postfixed with osmium tetroxide in Sørensen's buffer for an additional $3 \mathrm{~h}$. The specimens were dehydrated in graded alcohol concentrations and immersed in Epon with toluene as an intermediary solvent. Teased fiber preparations were prepared on sural and tibial nerves according to methods described by Dyck et al. (1984) and all quantification of teased fiber preparations was done according to the classification system developed by Dyck et al. (1984). A minimum of 125 fibers were counted for each nerve under blinded conditions. The number of fibers demonstrating condition "E" (myelin ovoids - wallerian degeneration) were counted per total number of fibers sampled and a percent degeneration score was calculated for each nerve. Statistical analyses included analysis of variance for repeated measures, paired and unpaired $t$-tests where appropriate, and Spearman rank correlation.

\section{Results}

The animals in this study exhibited typical physiologic profiles for insulin and non-insulin treatment (Table 1). There were no differences in beginning values for weight $(171 \pm 10$ vs $166 \pm 12)$ or Hct $(43 \pm 3$ vs $42 \pm 2)$ between the normal and high DPG groups. Two animals in the normal DPG untreated group died prior to sacrifice. The DPG + ATP levels in the 2 groups differed at baseline and remained so at sacrifice (Fig. 1). However, complete separation of DPG levels did not occur: two insulin-treated animals in the "normal" group had levels which overlapped with those seen in the "high" group.

All untreated animals in both the high and normal DPG groups demonstrated $0_{\%}^{\circ}$ degeneration in teased fiber preparations from sural and tibial nerves. All insulintreated animals from both groups displayed degeneration ranging from 0.4 to $17^{\circ}$. For the insulin-treated animals, there was an inverse correlation between DPG + ATP levels and percent degeneration $(r=-0.59$, $P<0.04$; Fig. 2). No significant correlation could be demonstrated between percent neuropathy and mean (weekly)

\section{TABILE 1}

TERMINAL VALUES

Mean $\pm S D$

\begin{tabular}{|c|c|c|c|c|c|}
\hline Group (n) & $\begin{array}{l}\text { Hct } \\
(0,0)\end{array}$ & $\begin{array}{l}\text { Insulin } \\
(\mu \mathrm{U} / \mathrm{ml})\end{array}$ & $\begin{array}{l}\text { Glucagon } \\
(\mathrm{pg} / \mathrm{ml})\end{array}$ & $\begin{array}{l}\text { Glucose } \\
(\mathrm{mg} / \mathrm{di})\end{array}$ & $\begin{array}{l}\text { Weight } \\
\text { (g) }\end{array}$ \\
\hline \multicolumn{6}{|c|}{ Controls (normal DPG) } \\
\hline Untreated (3) & $32 \pm 5$ & $5.9 \pm 2.3$ & $760 \pm 212$ & $727 \pm 26$ & $173 \pm 6$ \\
\hline Treated (5) & $42 \pm 2$ & $105.2 \pm 59.9$ & $225 \pm 52$ & $246 \pm 109$ & $249 \pm 17$ \\
\hline \multicolumn{6}{|l|}{ High DPG } \\
\hline Untreated (5) & $32 \pm 2$ & $4.8 \pm 1.8$ & $645 \pm 120$ & $755 \pm 12$ & $164 \pm 15$ \\
\hline Treated (5) & $39 \pm 5$ & $153.1 \pm 103.0$ & $212 \pm 32$ & $280 \pm 170$ & $241 \pm 6$ \\
\hline
\end{tabular}




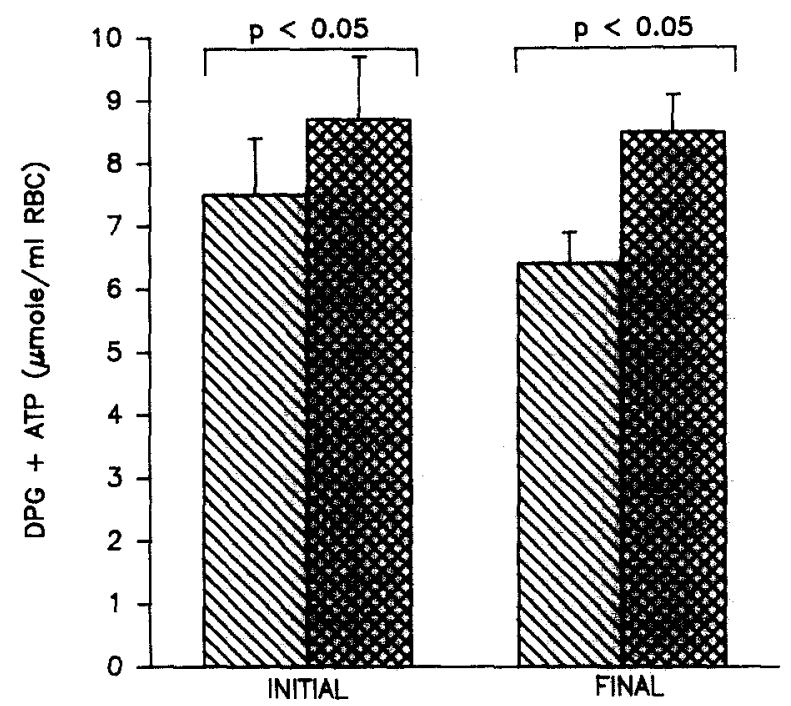

Fig. 1. Baseline and pre-sacrifice DPG + ATP levels in the normal DPG (single hatched) and high DPG (crosshatched) groups of treated and untreated animals.

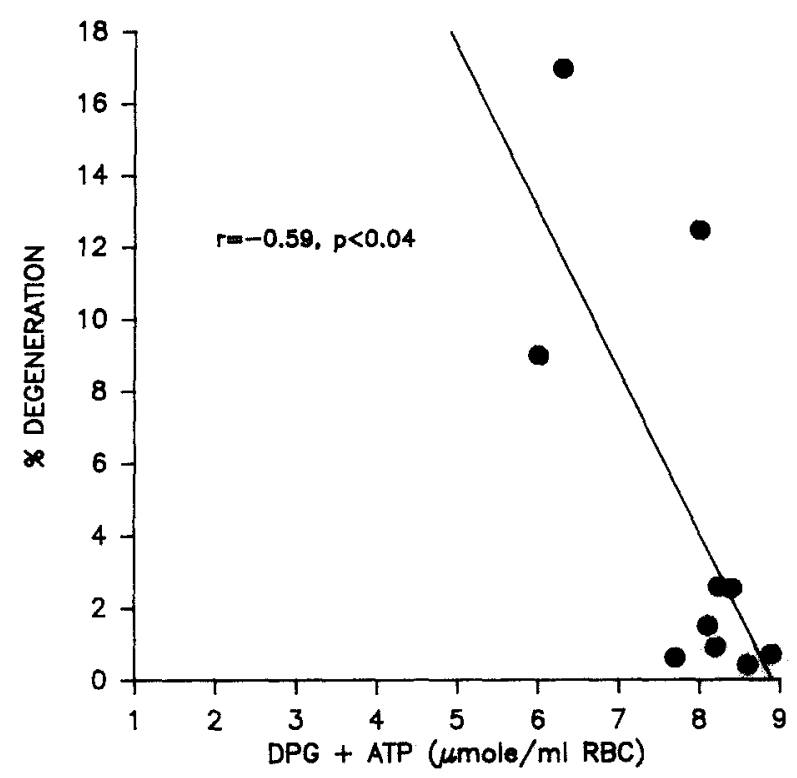

Fig. 2. DPG + ATP levels in insulin-treated rats $v 8 \%$ degeneration in the same animals (Spearman rank correlation).

blood glucose or with terminal or final blood glucose levels. Utilizing multiple regression analysis, neither glucagon, insulin, weight or glucose levels could be related to percent neuropathy after DPG + ATP levels were taken into account.

\section{Discussion}

The major finding in this study, that there is an inverse correlation between RBC levels of DPG and percent degen-

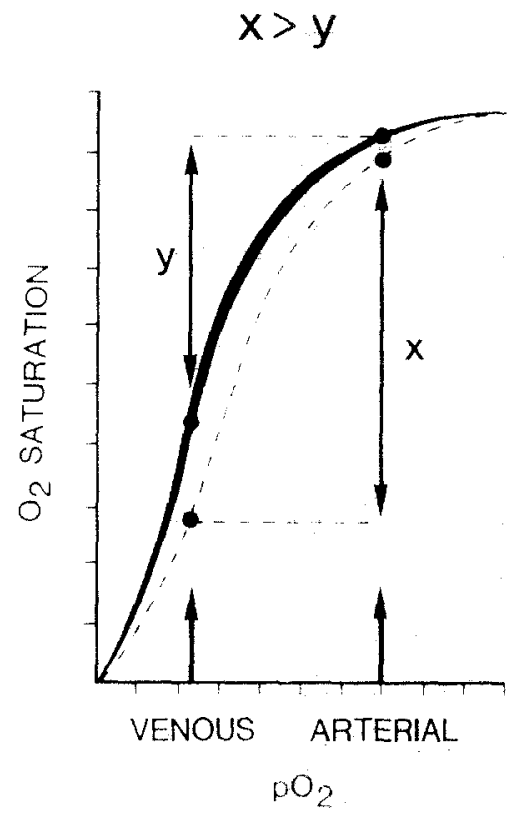

Fig. 3. Effect of $\mathrm{Hb}-\mathrm{O}_{2}$ shifts on $\mathrm{O}_{2}$ extraction. As the $\mathrm{P}_{50}$ increases (less $\mathrm{Hb}-\mathrm{O}_{2}$ affinity, dotted line), the arterial saturation changes little. However, the venous saturation decreases to a much greater degree with a resultant increase in the A- $\mathrm{V} \mathrm{O}_{2}$ difference, $x>y$ (see text).

eration supports the concept that tissue hypoxia induced by changing $\mathrm{Hb}-\mathrm{O}_{2}$ affinity may play a role in exacerbating diabetic peripheral neuropathy. Insulin has been shown to decrease the $\mathrm{P}_{50}$, defined as the partial pressure $\left(\mathrm{PO}_{2}\right)$ of oxygen required to half saturate hemoglobin (Shappell et al. 1975 ). When the $P_{50}$ decreases, the oxyhemoglobin dissociation curve shifts to the left (Fig. 3). Because the curves are flat on the top, the difference in saturation for a given $\mathrm{PO}_{2}$ on the arterial side is small; however, the difference in saturation for a given $\mathrm{PO}_{2}$ on the venous side is much greater. Thus, with a left-shifted curve, the arteriovenous oxygen difference is decreased, theoretically resulting in diminished tissue oxygen delivery. Each millimeter change in the $\mathbf{P}_{50}$ may result in as much as a $7 \%$ change in tissue oxygen saturation (Shappell et al. 1975). Ditzel has shown that the mean decrease in oxygen release calculated from the measured fall in the $\mathrm{P}_{50}$ following subcutaneous insulin in non-acidotic diabetics averaged $12 \%$ (Ditzel 1980; Standl et al. 1976).

Prominent among the factors known to affect $P_{50}$ is DPG. Increases in DPG produce increases in the $P_{50}$ or a rightward shift in the oxyhemoglobin dissociation curves resulting in enhanced tissue oxygenation, while decreases in DPG produce the opposite result. Changes in ATP produce similar effects to DPG (Ditzel 1980; Shappell et al. 1975).

Bolus administration of insulin lowers plasma inorganic phosphate with a resultant decrease in DPG production and a decrease in the $P_{50}$ (Ditzel 1980; Ditzel et al. 1976b). The relative tissue hypoxia induces compensatory micro- 
vascular vasodilation with both increased blood flow and capillary permeability. Over time, such metabolic fluxes may lead to significant hyperemia and tissue damage. These problems in tissue oxygenation induced by bolus insulin therapy are superimposed upon the reduced oxygen extraction caused by hyperglycemia and elevated levels of glycosylated hemoglobin since increased $\mathrm{HbA}_{1} \mathrm{C}$ produces a decrease in the $P_{50}$ with diminished tissue oxygen extraction (Ditzel 1976a, 1980; Ditzel et al. 1979).

Other investigators have reported a decrease in endoneurial $\mathrm{PO}_{2}$ in diabetic animals prompting them to hypothesize a vascular-hypoxia etiology for the peripheral nerve degeneration seen in diabetes (Dyck 1989; Low 1987). Such findings could be produced by affinity hypoxia with its resultant lack of tissue oxygen release.

Insulin injected as a bolus often produces hypoglycemia which has also been suggested as an etiologic factor in causing peripheral nerve degeneration (Jakobsen et al. 1987; Potter et al. 1988). We found no correlation between mean or trough blood glucose levels and percent degeneration in this study. It is likely that bolus insulin produces hypoglycemia and hypophosphatemia with decreased $\mathrm{P}_{50}$; however, in the present study, the differing DPG and $P_{50}$ levels may have obscured this relationship.

The evidence to date suggests that the etiology of diabetic peripheral neuropathy is the result of interaction among multiple factors including a direct action of insulin on peripheral nerve fibers which could at least partly explain the results observed (Dyck 1989; Greene et al. 1988; Low 1987). Although actual measurements of nerve oxygen tension were not made, data from this study lend indirect support to the mounting evidence that there is a hypoxic component contribution to the diabetic neuropathic condition; the exact mechanism whereby affinity hypoxia contributes to the production of peripheral neuropathy remains to be studied. Naturally, the relevance of results obtained in studies on induced diabetes in animals to the human diabetic condition considering factors such as varying induction time and genetic homogeneity remain to be proven.

Acknowledgement We thank Ms. MaryAnn Neel for her excellent technical assistance.

\section{References}

Brewer, G.J., O.I. Szamraj and V.L. Crews (1979) A genetic approach to producing oxygen affinity differences. Crit. Care Med.. 7(9):432-438.
Ditzel, J. (1976) Oxygen transport impairment in diabetes. Diabetes, 25 (Suppl. 2): 832-838.

Ditzel, J. (1980) Affinity of hypoxia as a pathogenetic factor of microangiopathy with particular reference to diabetic retinopathy. Acta Endocrinol., 94 (suppl 238): 39-55.

Ditzel, J. and E. Standl (1975) The oxygen transport system of red blood cells during diabetic ketoacidosis and recovery. Diabetologia, 11 : $255-260$.

Ditzel, J. and E. Standl (1976) Plasma Pi and erythrocyte 2,3-diphosphoglycerate concentrations of non-acidotic diabetics in various degrees of metabolic control. Clin. Chem., 22 (4): 550-551.

Ditzel, J., C. Hau and N. Daugaard (1977) Effect of the diphosphonate ethane-I-hydroxy-I, I-diphosphonate (EHDP) on hemoglobin oxygen affinity of diabetic and healthy subjects. Microvasc. Res.. 13: $355-361$.

Ditzel, J., N.V. Nielsen and J.-J. Kjaergaard (1979) Hemoglobin Alc and red cell oxygen release capacity in relation to carly retinal changes in newly discovered overt and chemical diabetics. Metabolism, 28 (4): $440-447$.

Dyck, P.J. (1989) Hypoxic neuropathy: Does hypoxia play a role in diabetic neuropathy? Neurology, 39: 111-118.

Dyck, P.J., J. Karnes, A. Lais et al. (1984) Pathologic alterations of the peripheral nervous system of humans. In: P.I. Dyck. P.K. Thomas, E.H. Lambert and R. Bunge (Eds.). Peripheral Neuropathy, pp. 760-870, W.B. Saunders, Philadelphia, PA.

Dyck, P.J., A. Windebank, H. Yasuda, F.J. Service, R. Rizza and B. Zimmerman (1985) Diabetic neuropathy. Adv. Exp. Med. Biol., 189: 305-320.

Greene, D.A., S.A. Lattimer and A.A.F. Sima (1988) Perspective in diabetes: are disturbances of sorbitol, phosphoinositide and $(\mathrm{Na}, \mathrm{K})$ ATPase regulation involved in the pathogenesis of diabetic neuropathy? Diabetes, 37: 688-693.

Heding, L.G. (1972) Determination of total serum insulin (IRI) in insulintreated diabetic patients. Diabetologia, 8: 260-266.

Jakobsen, J. and P. Sidenius (1987) Hypoglycemic neuropathy. In: P.J. Dyck, P.K. Thomas, A.K. Asbury, A.I. Winegard and D. Porte (Eds.), Diabetic Neuropathy, pp. 94-99. W.B Saunders, Philadelphia, PA.

Low, P.A. (1987) Recent advances in the pathogenesis of diabetic neuropathy. Muscle Nerve, 10:121-128.

Potter, C.G., A.K. Sharma, M. Farber and R.G. Peterson (1988) Hypoglycemic neuropathy in experimental diabetes. J. Neurol. Sci., 88: 293-301.

Shappell, S.D. and C.J.M. Lenfant (1975) Physiological role of the oxyhemoglobin dissociation curve. In: D.M. Surgenor (Ed.), The Red Blood Cell, 2nd edn., p. 861, Academic Press, New York.

Standl, E. and J. Ditzel (1976) The effect of red cell 2,3-DPG changes induced by diabetic ketoacidosis on parameters of the oxygen dissociation curve in man. Adv. Exp. Med. Biol., 75: 89-95.

Thomas, P.K. and S.G. Eliasson (1984) Diabetic neuropathy. In: P.J. Dyck, P.K. Thomas, E.H. Lambert and R. Bunge (Eds.), Peripheral Neuropathy, pp. 1773-1810, W.B. Saunders, Philadelphia, PA.

Unger, R.H., A.M. Eisentraut, M.S. McCall and L.L. Madison (1962) Measurement of endogenous glucagon in plasma and the influence of blood glucose upon its secretion. J. Clin. Invest., 41: 682-689.

Windebank, A.J. (1983) Diabetic control and peripheral neuropathy. Mayo Clin. Proc., 58: 344-346. 